PRINT ISSN 1119-8362

Electronic ISSN 1119-8362
Full-text Available Online at https://www.ajol.info/index.php/jasem http://ww.bioline.org.br/ja
J. Appl. Sci. Environ. Manage.

Vol. 25 (8) 1449-1452 August 2021

\title{
Bayesian Change Point Detection of Vegetation Cover Dynamics of Akure Forest Reserve, Ondo State in Southwestern, Nigeria
}

\section{*UKOHA, PA; OKONKWO, SJ; ADEWOYE, AR}

\author{
Forest Ecosystem \& Climate Change Modelling Group, Department of Environmental Modelling and Biometrics, Forestry Research \\ Institute of Nigeria \\ *Corresponding Author Email: amarachipeaceukoha@gmail.com
}

\begin{abstract}
This study uses satellite acquired vegetation index data to monitor changes in Akure forest reserve. Enhanced Vegetation Index (EVI) time series datasets were extracted from Landsat images; extraction was performed on the Google Earth Engine (GEE) platform. The datasets were analyzed using Bayesian Change Point (BCP) to monitor the abrupt changes in vegetation dynamics associated with deforestation. The BCP shows the magnitude of changes over the years, from the posterior data obtained. BCP focuses on changes in the long-range using Markov Chain Monte Carlo (MCMC) methods, this returns posterior probability at $>0.5 \%$ of a change point occurring at each time index in the time series. Three decades of Landsat data were classified using the random forest algorithm to assess the rate of deforestation within the study area. The results shows forest decrease in 2000 (97.7\%), 2010 (89.4\%), 2020 (84.7\%) and non-forest increase 2000 (2.0\%), 2010 $(10.6 \%), 2020(15.3 \%)$. Kappa coefficient was also used to determine the accuracy of the classification.
\end{abstract}

\section{DOI: https://dx.doi.org/10.4314/jasem.v25i8.25}

Copyright: Copyright $(2021$ Ukoha et al. This is an open access article distributed under the Creative Commons Attribution License (CCL), which permits unrestricted use, distribution, and reproduction in any medium, provided the original work is properly cited.

Dates: Received: 10 May 2021; Revised: 28 June 2021; Accepted: 01 July 2021

Keywords: Bayesian Change Point, EVI, MCMC, Random Forest

Forest degradation has become a global concern especially forest conversion to non-forest. These can be a result of any combination of short-term and longer-term variability attributable to climate change, and the impacts of human activities are accelerating forest changes worldwide. Forest concepts and definitions affect our interpretation and understanding of forest changes (Chazdon et al., 2016). Forests, specifically protected reserve areas need a monitoring system as fundamental tools to support the management of landscapes, ecosystems, and biodiversity (Fischer, 2007). Understanding forest changes provide valuable knowledge for effective forest management and policy development (Kennedy et al., 2014). Many approaches have been proposed to detect forest changes such as spatial resolution satellite data. Satellite imagery is used to evaluate forest changes by providing a means to estimate forest conditions in a spatially explicit manner, and assess current and historical trends of deforestation and forest degradation (Baker et al., 2010). Changes in land cover lead to the forest landscapes being at stake which could lead to loss of habitat and biodiversity (Bennett, 2010). A statistical approach is a valuable tool in detecting changes given a sequence of data over time. Bayesian approaches have been adopted using Gaussian assumption when detecting a change point, also to obtain posterior probabilities estimation approach derived based on maximum likelihood (Hawkins, 2001). Gaussian models describe possible changes in level and error variance and approximate the posterior posterior means of the parameters. The Bayesian approach makes use of reversible jump Markov Chain Monte Carlo (MCMC) (Green et al., 1995).

\section{MATERIALS AND METHODS}

Study Area: Akure forest reserve is located in Akure South Local government area of Ondo State in Southwestern, Nigeria (Figure 1). It lies between the range of latitudes $7^{\circ} 16^{\prime} \mathrm{N}$ and $5^{\circ} 9^{\prime} \mathrm{E}$ and longitude $7^{\circ} 18^{\prime} \mathrm{N}$ and $5^{\circ} 11^{\prime} \mathrm{E}$ covering the total land area of $66 \mathrm{~km}^{2}$, its elevation ranges from $216 \mathrm{~m}$ to $504 \mathrm{~m}$.

Data Extraction: Three decades of supervised classification (Forest and Non- Forest) were performed within the study area using the random forest classifier on the Google Earth Engine (GEE) platform. GEE is a cloud web-based computing platform that has lots of data such as satellite images, climatic and environmental datasets. The points for land classes were extracted for the classification. These points were split into $70 \%$ for training and 30\% for validation with the aid of python and java scripting. Kappa coefficient was also assessed to ascertain the accuracy of the classified images. 


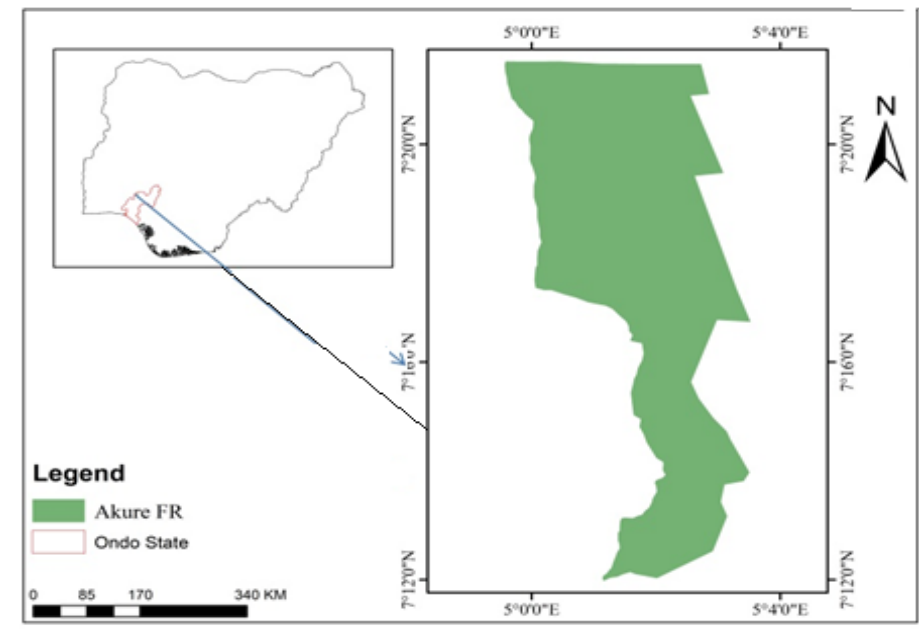

Fig 1: Study area Map

Enhance Vegetation Index (EVI): Enhance Vegetation Index of time series was extracted in GEE using Landsat collection of images which covers $30 \mathrm{~m}$ resolution for every 16 days. The time series data was from 15-02-2000 to 22-12-2020 with 186 observations. EVI was used because of its sensitivity to changes in areas with high biomass and dense vegetation. Also, it reduces the influence of atmospheric conditions on vegetation index and correct for canopy background noise. (Huete, 2002)

$$
\mathrm{EVI}=2.5 * \frac{(N I R-R E D)}{(N I R+C 1 * R E D-C 2 * \text { Blue }+L}
$$

$L=1, C 1=6, C 2=7.5$, and $G$ (gain factor $)=$ 2.5. Where NIR/Red/Blue are the spectral bands, $L$ is the values that adjust the canopy background, and $C 1, C 2$ are the coefficients of the aerosol resistance and values from the blue band. The EVI time series extracted was used to detect changes and breakpoints using Bayesian Change and Change Point packages in R-studio.

Bayesian Change Point (BCP): The BCP package in $\mathrm{R}$-studio is designed to perform analysis of univariate time series. It returns the posterior probability of a change point occurring at each time index in the series. $\mathrm{BCP}$ detection rates depend on the magnitude of changes using Markov Chain Monte Carlo (MCMC) (Erdman, 2008) and (Barry and Hartigan, 1993). The algorithm begins with the partition $\rho=$ $\left(U_{1}, U_{2}, \ldots, U_{n}\right)$, where $n$ is the number of observations and $U_{i}=1$ indicates a change point at position $i+1$; we initialize $U_{i}$ to 0 for all $i<n$, with $U_{n} \equiv 1$. In each step of the Markov chain, at each position $i$, a value of $U_{i}$ is drawn from the conditional distribution of $U_{i}$ given the data and the current partition. Let $\mathrm{b}$ denote the number of blocks obtained if $U_{i}=0$, conditional on $U_{j}$, for $i \neq j$.

The transition probability, $p$, for the conditional probability of a change at the position $i+1$, is obtained from the simplified ratio presented in Barry and Hartigan, (1993):

$$
\begin{gathered}
\frac{P_{i}}{1-P_{i}}=\frac{P\left(U_{i}=1 \mid X, U_{j, j \neq i}\right)}{P\left(U_{i}=0 \mid X, U_{j, j \neq i}\right)} \\
=\frac{\int_{0}^{p_{0}} p^{b}(1-p)^{n-b-1} d p}{\int_{0}^{p_{0}} p^{b-1}(1-p)^{n-b} d p} \times \frac{\int_{0}^{w_{0}} \frac{w^{b / 2}}{\left(W_{1}+B_{1} w\right)^{(n-1) / 2}} d w}{\int_{0}^{w_{0}} \frac{w^{(b-1) / 2}}{\left(W_{0}+B_{0} w\right)^{(n-1) / 2}} d w}
\end{gathered}
$$

Where $W_{0}, B_{0}, W_{1}$ and $B_{1}$ are within and between block sums of squares obtained when $U_{i}=0$ and $U_{i}=$ 1 respectively, and $X$ is the data. Also, $0 \leq p_{0}, w_{0} \leq$ 1 chosen so that this method is very effective in situations when there aren't too many changes $\left(p_{0}\right.$ is small) and when the changes are of reasonable size ( $w_{0}$ is small) (Barry and Hartigan, 1993).

\section{RESULT AND DISCUSSION}

Land Cover Analysis: Figure 2 shows the rate at which the forest reduces over 3 decades in percentages.

Enhance Vegetation Index (EVI) Analysis: Figure 3 shows the EVI time series data that was used to monitor the forest changes within Akure Forest Reserve. EVI was used due to its sensitivity to vegetative areas; the data shows the trend of changes over time. Bayesian Change Point Analysis: Figure 4 shows the proportion of iterations resulting in a change point at each interval while the second graph in fig4 shows the data along with the posterior mean of each interval. Markov Chain Monte Carlo returns the probability of change points in the observations. The 
lower posterior probability plot shows that different locations indicate a high probability of changes. This estimates the probability of a change point in an interval starting from the beginning to the end of the time series observation. The result shows the dates where the changes were observed, the probability at > $0.5 \%$, and the magnitude of changes. It shows that there is a probability of the forest decreasing in the future.

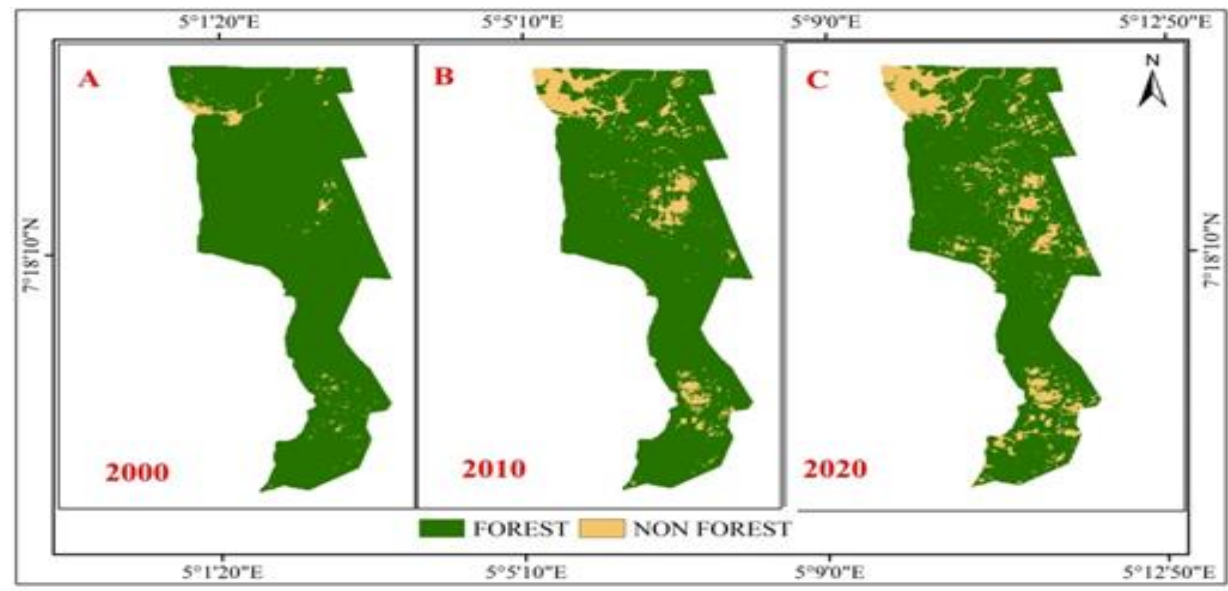

Fig 2: Land cover maps. A = Forest: $97.7 \%$; non-forest: $2.0 \%$; Overall accuracy: $0.77 \%$; B = Forest: $89.4 \%$; non-forest: $10.6 \%$; Overall accuracy: $0.84 \%$; C: Forest: $84.7 \%$; non-forest: $15.29 \%$; Overall accuracy: $0.81 \%$

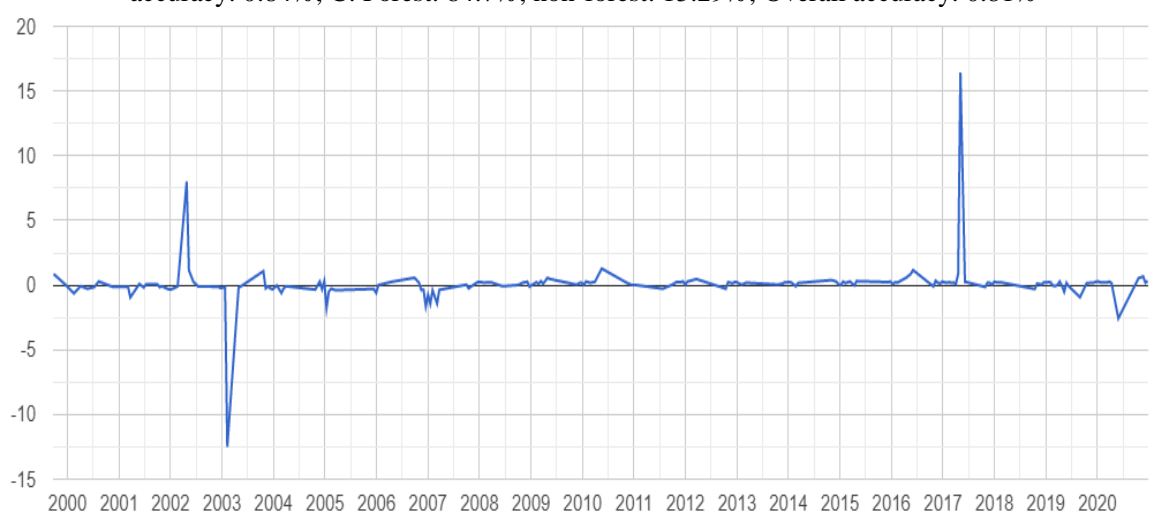

Fig 3: Enhance Vegetation Index (EVI) Time Series

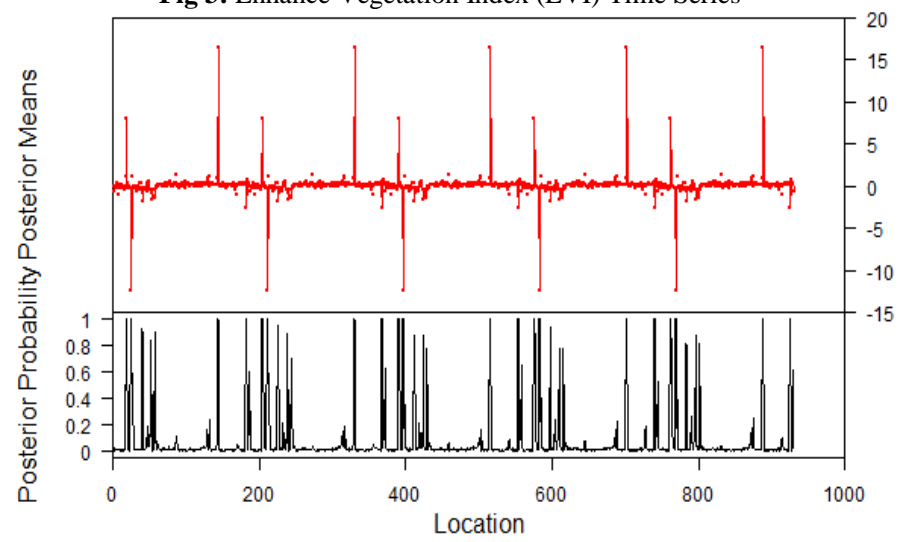

Fig 4: Posterior means and Probability of Change

With the aid of BCP algorithm changes were detected within the study area. The study detected various anthropogenic changes from the year 2000 to 2020 changes. Figure 5 shows deforestation in the Akure Forest reserve is on a phenomenal increase, which could continue in the nearest feature if necessary precautions are not taken. 


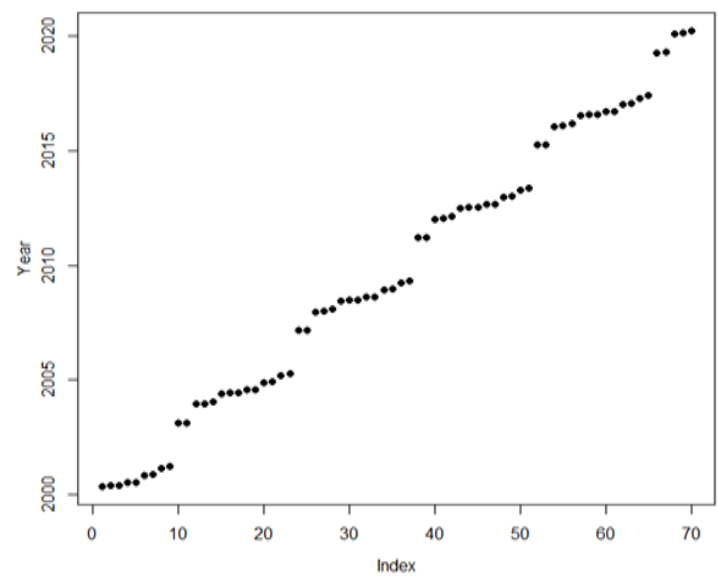

Fig 5: Years of Changes

Conclusion: Bayesian change points analysis showed the changes over the years. From the posterior data obtained, we were able to detect the changes. Forest cover anomaly detection using a combination of robust data mining techniques, and practical remote sensing methodologies is an invaluable tool in forest monitoring and conservation.

\section{REFERENCE}

Baker,D; Richards, G; Grainger, A; Gonzalez, P; Bro wn, S; DeFries, R; Held, A; Kellndorfer, J;Ndund a, P; Ojima, D; Skrovseth, P; Souza, C and Stolle, F (2010). Achieving forest carbon information with higher certainty. Environ Sci. Policy, 13: 249-260

Barry, D; Hartigan, JA (1993). A Bayesian analysis for change point problems, J Am Stat Assoc, 88: 309-319.

Bennett, AF; Saunders, DA (2010). Habitat fragmentation and landscape change. Conservation Biology for All. Oxford University Press. 93: 1544-1550
Chazdon, RL; Brancalion, $\mathrm{P} \mathrm{H}$; Laestadius, L; BennettCurry, A; Buckingham, K; Kumar, C; Moll-Rocek, J; Vieria, ICG; Wilson, SJ (2016). When is a forest a forest? Forest concepts and definitions in the era of forest and landscape restoration. Ambio. 45: 538-550

Erdman, C; Emerson, JW (2008). A fast Bayesian change point analysis for the segmentation of microarray data. Bioinform. 24:2143-2148

Fischer, J; Lindenmayer, DB (2007). Landscape modification and habitat fragmentation: a synthesis. Glob. Ecol. Biogeogr. 16: 265-280

Green, PJ (1995). Reversible Jump Markov Chain Monte Carlo computation and Bayesian model determination. Biometrika 82(4):711-732

Hawkins, DM (2001). Fitting Multiple Change-Points to Data. Comput Stat Data Anal, 37, 323-341

Huete, K; Didan, T; Miura, E; Rodriguez, X; Gao, L; Ferreira (2002). Overview of the radiometric and biophysical performance of the MODIS vegetation indices. Remote Sens. Environ. 83:195-213.

Kennedy, RE; Andréfouët, S; Cohen, WB; Gómez, C; Griffiths, P; Hais, M; Healey, SP; Helmer, EH; Hostert, P; Lyons, MB; Meigs, GW; Pflugmacher, D; Phinn, S; Powell, SL; Scarth, P; Sen, S; Schroeder, TA; Schneider, A; Sonneschein, R; Vogelmann, JE; Wulder, MA; Zhu, Z (2014). Bringing an ecological view of change to Landsatbased remote sensing. Front. Ecol. Environ.12:339-346. 